\title{
Study and Analysis by Numerical Simulation of a Solar Continuous Adsorption Chiller Rabah GOMRI and Billel MEBARKI
}

\author{
Department of Genie Climatique/ University Constantine 1 \\ 25000 Constantine, Algeria \\ rabahgomri@yahoo.fr
}

\begin{abstract}
Keywords: Adsorption; refrigeration; Solar Energy; Mass recovery; Performance.
\end{abstract}
\begin{abstract}
Environment and energy problems over the world have motivated researchers to develop energy systems more sustainable, having as one of the possible alternative the use of solar energy as source for cooling systems. Adsorption refrigeration systems are regarded as environmentally friendly alternatives to conventional vapour compression refrigeration systems, since they can use refrigerants that do not contribute to ozone layer depletion and global warming. In this paper a performance comparison between a solar continuous adsorption cooling system without mass recovery process and solar continuous adsorption cooling system with mass recovery process is carried out. Silica-Gel as adsorbent and water as refrigerant are selected. The results show that the adsorption refrigeration machine driven by solar energy can operate effectively during four months and is able to produce cold continuously along the 24 hours of the day. The importance of the mass recovery is proved in this study by increasing the coefficient of performance and the cooling capacity produced. For the same cooling capacity produced, the required number of solar collectors with mass recovery system is lower than the required number of solar collectors in the case of the refrigeration unit without mass recovery. For the same cooling capacity the system with mass recovery process allowed lower generation temperature.
\end{abstract}

\section{Introduction}

The production of cold water for air-conditioning uses several refrigeration cycles. Among these cycles the adsorption refrigeration systems have attracted more attention in research and development. Adsorption refrigeration systems employ natural substances as refrigerant, such as water, methanol and ammonia among others, which have zero GWP and ODP. Adsorption refrigeration systems refrigeration systems can be powered with waste heat or solar energy, hence could contribute greatly to electricity energy conservation. Silica-gel is most widely used adsorbent while water, is most widely used adsorbate (refrigerant) in solar-powered or waste heat-driven adsorption refrigeration systems [1]. Several researchers have studied adsorption refrigeration system [2-9]. In this paper a performance comparison between a solar continuous adsorption cooling system without mass recovery process and solar continuous adsorption cooling system with mass recovery process is carried out using the pair silica-gel/water as adsorbent and adsorbate (refrigerant) respectively.

\section{System Description}

Fig. 1 presents the working principle of the solar adsorption chiller. The proposed system consists of a two-bed adsorption chiller, solar collectors and a storage tank of the solar energy.

Fig.2. presents the description of the two-bed adsorption chiller with and without mass recovery. The two-bed adsorption chiller is composed of an evaporator, a condenser and a pair of sorption elements (SE1 and SE2). ES1 and ES2 are connected through the valve 5. The operation of the machine goes through six modes. 


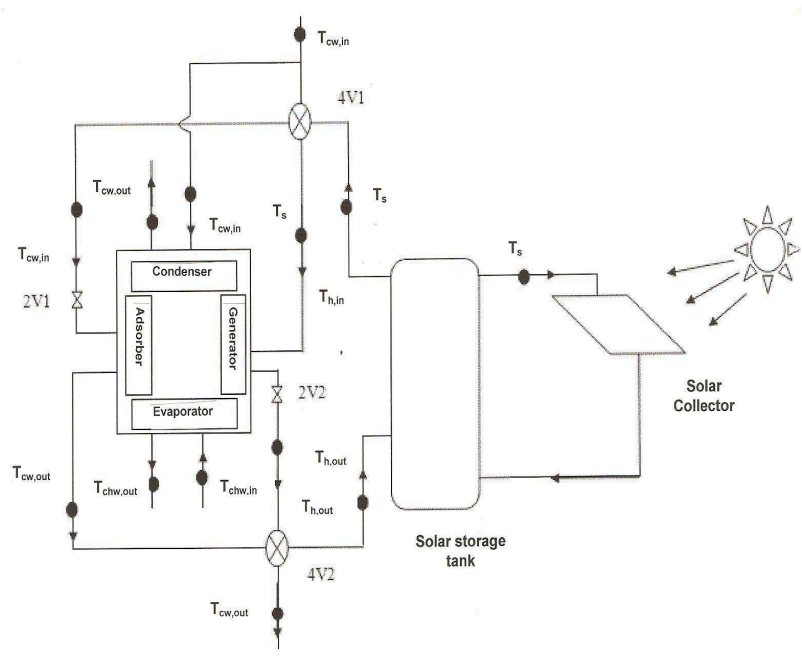

Fig. 1: Schematic diagram of the coupling of solar system with the adsorption chiller

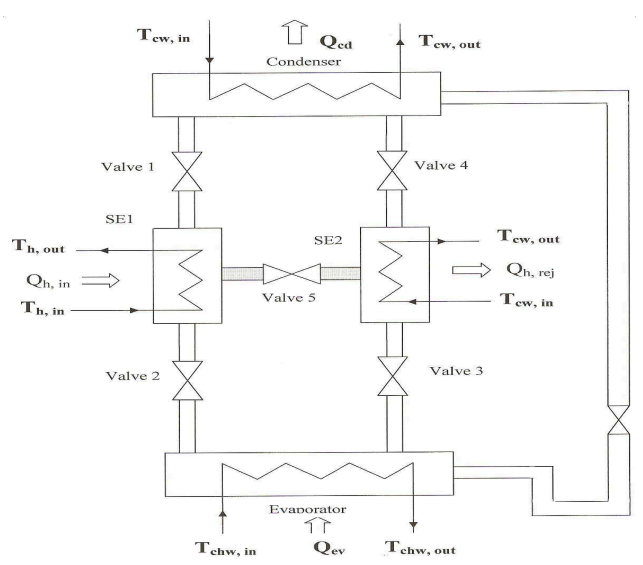

Fig. 2 Schematic diagram of two-bed adsorption chiller with mass recovery

\section{Mathematical Model}

In this study the following assumptions were adopted:

- It is considered that the system is well insulated then there are no heat losses to the environment.

- All the quantity of vapour transferred in the mass recovery mode is adsorbed by the adsorbent

- It is assumed that the gases are perfect.

- The values of the pressure and temperature are uniform in the adsorber, the generator, the condenser and the evaporator.

According to these assumptions, the dynamic behavior of heat and mass inside the different components of the adsorption chiller has been written.

\section{System Performance}

The cooling output $\mathrm{Q}_{\mathrm{ev}}$, the heat supplied to desorber $\mathrm{Q}_{\mathrm{h} \text {,in }}$ and COP are calculated by the following relations:

$$
\begin{aligned}
& \mathrm{Q}_{\mathrm{ev}}=\frac{\int_{0}^{\mathrm{t}_{\mathrm{cycle}}} \dot{\mathrm{m}}_{\text {chw }} \cdot C \mathrm{p}_{\text {chw }} \cdot\left(\mathrm{T}_{\text {chw }, \text { out }}-\mathrm{T}_{\text {chw }, \text { in }}\right) \cdot \mathrm{dt}}{\mathrm{t}_{\text {cycle }}} \\
& \mathrm{Q}_{\mathrm{h}, \text { in }}=\frac{\int_{0}^{\mathrm{t}_{\text {cyle }}} \dot{\mathrm{m}}_{\mathrm{hw}} \cdot C \mathrm{C}_{\mathrm{hw}} \cdot\left(\mathrm{T}_{\mathrm{s}}-\mathrm{T}_{\mathrm{hw}, \text { out }}\right) \cdot \mathrm{dt}}{\mathrm{t}_{\text {cycle }}} \\
& \mathrm{COP}=\frac{\mathrm{Q}_{\mathrm{ev}}}{\mathrm{Q}_{\mathrm{h}, \text { in }}}
\end{aligned}
$$

\section{Results and Discussion}

In order to study the influence of the mass recovery on the performance of the refrigeration unit, a Fortran program based on the resolution of simultaneous differential equations according to the operation modes of the two-bed adsorption chiller was written assuming that during one hour the cycles of the adsorption chillers are identical (it is considered that the temperature of the storage tank is constant for one hour time). Figs. 3-6 show the variation of the coefficient of performance $\mathrm{COP}$, the cooling capacity $\mathrm{Q}_{\mathrm{ev}}$, the temperature of the solar energy storage tank $\mathrm{T}_{\mathrm{s}}$ and heat supplied to the generator $\mathrm{Q}_{\mathrm{h} \text {,in }}$ for the day $17^{\text {th }}$ of the month of July in Constantine (Altitude $689 \mathrm{~m}$, Latitude 
$36.28 \mathrm{~N}$, Longitude $6.37 \mathrm{E}$ ). It can be seen that the variation of the four parameters are identical and there are four zones:

The first zone between $8 \mathrm{hr}$ and $9 \mathrm{hr}$ : there is a decrease of the four parameters. At $8 \mathrm{hr}$ the circuit between the solar collectors and the storage tank is open. Solar radiation received by the solar collectors is lower than thermal losses of the solar collectors therefore; the outlet temperature of the solar collector is lower than the temperature of the storage tank which implies a cooling of the water in the storage tank which also leads to a decrease of the temperature of the storage tank $\mathrm{T}_{\mathrm{s}}$ (Fig. 5). The decrease of the temperature $T_{\mathrm{s}}$ causes an increase of the minimum mass which reduces the mass cycled and in turn causes a decrease in refrigeration load $Q_{\mathrm{ev}}$ (Fig. 4) which leads to a decrease in the COP values (Fig. 3).

The second zone between $9 \mathrm{hr}$ and $18 \mathrm{hr}$ : there is an increase of the four parameters to reach a maximum at $18 \mathrm{hr}$. The circuit between the solar collectors and the storage tank is open. Solar radiation received by the collectors exceeds the heat losses. Therefore; the collectors temperature output is lower than the temperature of the storage tank which involves heating the water in the storage tank resulting in an increase of the temperature $T_{s}$ (Fig. 5). Increasing the temperature $T_{s}$ of the storage tank which leads to a decrease of the minimum mass and that increases the mass cycled resulting in an increase of the cooling output $\mathrm{Q}_{\mathrm{ev}}$ (Fig. 4) which gives an increase in the coefficient of performance COP (Fig. 3).

The third zone between $18 \mathrm{hr}$ and $21 \mathrm{hr}$ : The four parameters decrease. The circuit between the solar collectors and the storage tank is open until $21 \mathrm{hr}$. Solar radiation received by solar collectors is lower than thermal losses of the collectors. Therefore, the outlet temperature of the solar collector is lower than the temperature of the storage tank which leads to a cooling of the storage tank resulting in a decrease in the temperature $T_{\mathrm{S}}$ (Fig. 7). The decrease of the temperature $T_{\mathrm{S}}$ causes an increase of the minimum refrigerant mass which reduces the mass cycled and causes a reduction in the refrigeration load $Q_{\mathrm{ev}}$ (Fig. 4) which gives a decrease in the COP of the chiller (Fig. 3).

The fourth zone between $21 \mathrm{hr}$ and $7 \mathrm{hr}$ : there is a decrease of the four parameters but with different slopes. The circuit between the collectors and the storage tank is closed. The tank temperature $\mathrm{T}_{\mathrm{s}}$ decreases due to the heat losses from the storage tank and the heat extracted to realize the desorption process. The decrease of the temperature $T_{\mathrm{s}}$ (Fig. 5) causes an increase of the minimum mass which reduces the mass cycled resulting in a decrease in refrigeration load $Q_{\mathrm{ev}}$ (Fig. 4) which implies a decrease in the cycle COP (Fig. 3).

It can be seen also that:

From 3 to 7 o'clock, the power consumed by the generator of the refrigeration unit with mass recovery is greater than the power consumed by the generator of the refrigeration unit without mass recovery (Fig. 6). The increase of the heat supplied to the generator between $3 \mathrm{hr}$ and $7 \mathrm{hr}$ is due to the low values of the storage tank temperature in the case of adsorption chiller without mass recovery which approach the temperatures limits of desorption phenomenon implying a low power consumption of the generator. The coefficient of performance of the refrigeration unit with mass recovery is greater than the coefficient of performance of the refrigeration unit without mass recovery (Fig. 5). The production of the refrigeration chiller with mass recovery is greater than the cooling output of the refrigeration unit without mass recovery (Fig. 4). The temperature of the storage tank installed with the adsorption chiller with mass recovery is higher than the temperature of the storage tank installed with the refrigeration unit without mass recovery (Fig. 5). Between 8 and 3 o'clock, power consumed by the generator of the refrigeration unit with mass recovery is lower than the power consumed by the generator of the refrigeration unit without recovery of the mass (Fig. 5). The cooling load production of adsorption chiller with mass recovery is greater than the cooling load of adsorption chiller without mass recovery and the generation heat in the case with mass recovery is lower than the generation heat in the case without mass recovery which explains the higher values of the coefficient of performance of the adsorption chiller with mass recovery. 


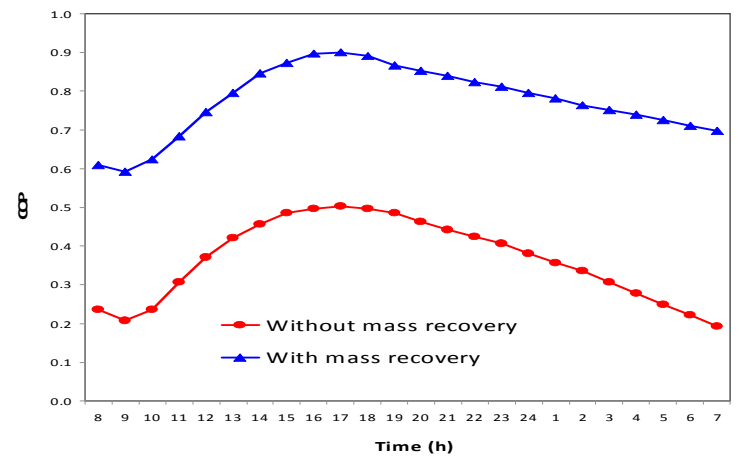

Fig. 3 Variation of the COP versus time

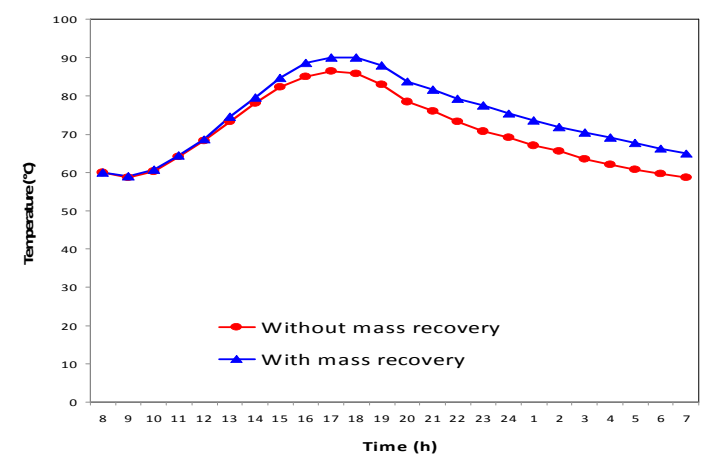

Fig. 5 Variation of the temperature of the with tank as a function of time

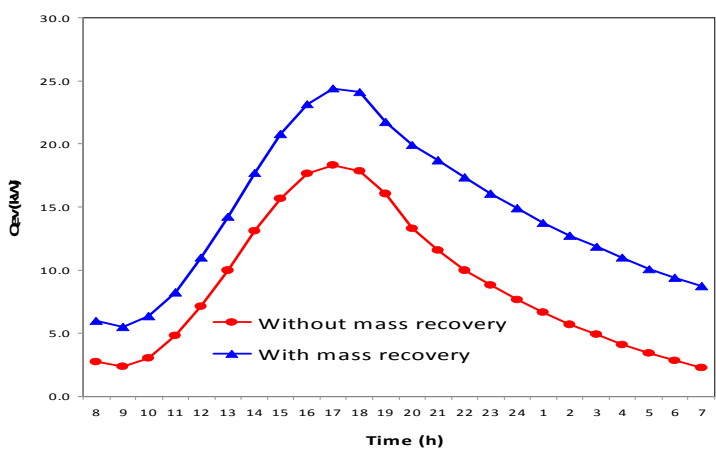

Fig. 4 Variation of the refrigeration plant with time

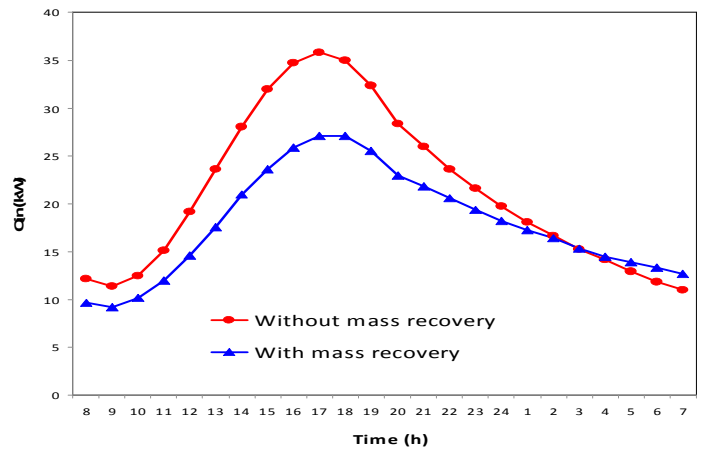

Fig. 6 Variation of the heat generator respect to time

Fig. 7 shows the variation of the coefficient of performance of the two-bed adsorption refrigeration unit with and without mass recovery as a function of generation temperature. It is clear that the coefficient of performance of the adsorption refrigeration unit with mass recovery is greater than the refrigeration unit without mass recovery. The adsorption refrigeration unit with mass recovery is more efficient than the refrigeration unit without mass recovery with low generation temperatures (minimum generation temperature is about $57^{\circ} \mathrm{C}$ ). Fig. 8 shows the variation of the cooling production versus the generation temperature of the adsorption chiller with and without mass recovery. It is clear that the cooling production of the adsorption chiller with mass recovery is greater than the refrigeration unit without mass recovery. So, for the same cooling power produced, the temperature of generation with the refrigeration unit with mass recovery is lower than the refrigeration unit without mass recovery which reduces the number of solar collectors needed by the system.

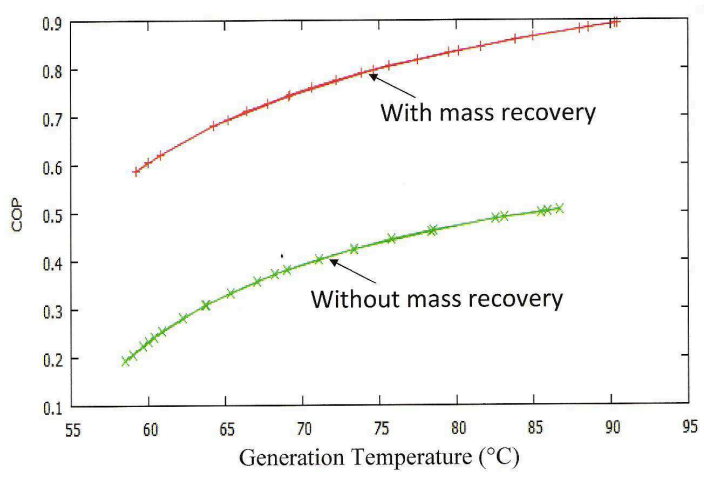

Fig. 7 Variation of the coefficient of performance against the generation temperature

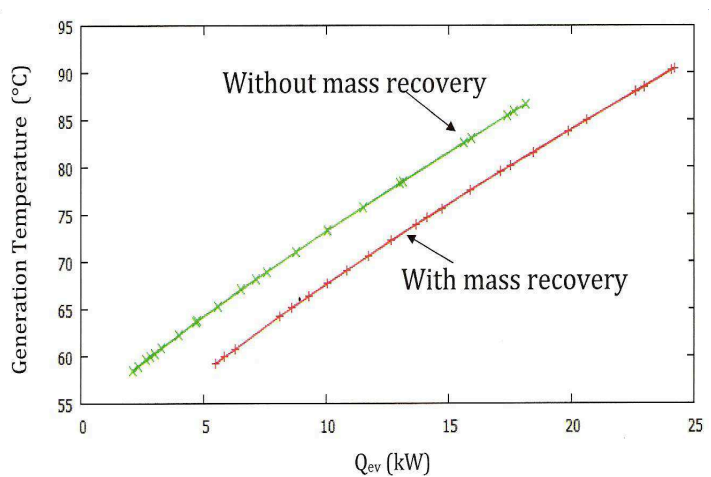

Fig. 8 Variation of the refrigeration load according to the generation temperature 
To ensure constant refrigeration load an auxiliary heat source is used. In the present study for a cooling load of $24.2 \mathrm{~kW}$ the system need $27.1 \mathrm{~kW}$. It is found that the auxiliary heat source covers about $34 \%$ of the total energy required and solar energy covers about $66 \%$ of the total energy required which shows the interesting use of solar energy.

\section{Conclusion}

The results obtained allow us to draw the following conclusions:

- The simulated results show that the adsorption chiller driven by solar energy can operate effectively during four months and is able to produce cold continuously along the 24 hours of the day.

- For the couple silica-gel/water the minimum generation temperature is about $57^{\circ} \mathrm{C}$.

- The importance of the mass recovery is proved in this study by increasing the coefficient of performance and the cooling capacity produced.

- For the same cooling capacity produced, the required number of solar collectors with mass recovery system is lower than the required number of solar collectors in the case of without mass recovery.

- For the same cooling capacity the system with mass recovery process allowed lower generation temperature

\section{References}

[1] D. Wang, J. Zhang, X. Tian, D. Liu, K. Sumathy. Progress in silica gel-water adsorption refrigeration technology, Renewable and Sustainable, Energy Reviews. 30 (2014) 85-104.

[2] X.J. Zhang, R.Z. Wang. Design and performance simulation of a new solar continuous solid adsorption refrigeration and heating hybrid system, Renewable Energy. 27 (2002) 401-415

[3] A. Akahira, K.C.A. Alam, Y. Hamamoto, A. Akisawa, T. Kashiwagi, Experimental investigation of mass recovery adsorption refrigeration cycle, International Journal of Refrigeration. 28 (2005). 565-572.

[4] T.Miyazaki, A. Akisawa, B.B. Saha, I.I. El-Sharkawy, A. Chakraborty, A new cycle time allocation for enhancing the performance of two-bed adsorption chillers, International Journal of Refrigeration, 32 (2009) 846-853.

[5] A. El Fadar, A. Mimet, M. Perez-Garcia, Study of an adsorption refrigeration system powered by parabolic trough collector and coupled with a heat pipe, Renewable Energy. 34 (2009) 22712279.

[6] C.J. Chen, R.Z. Wang, Z.Z. Xia, J.K. Kiplagat, Study on a silica gel-water adsorption chiller integrated with a closed wet cooling tower, International Journal of Thermal Sciences.49(2010) 611-620.

[7] N. H. Abu-Hamdeh, K. Alnefaie, K.H. Almitani, Design and performance characteristics of solar adsorption refrigeration system using parabolic trough collector: Experimental and statistical optimization technique, Energy Conversion and Management, 74 (2013) 162-170.

[8] H.Z.Hassan, A.A. Mohamad, Thermodynamic analysis and theoretical study of a continuous operation solar-powered adsorption refrigeration system, Energy. 61 (2013) 167-178.

[9] Z.S. Lu, R.Z. Wang, Performance improvement by mass-heat recovery of an innovative adsorption air-conditioner driven by $50-80^{\circ} \mathrm{C}$ hot water, Applied Thermal Engineering. 55 (2013) 113-120. 